\title{
Planejamento de ensino de língua portuguesa como objeto de estudo na formação de professores
}

\author{
Edmilson Luiz Rafael ${ }^{1}$ \\ Programa de Pós-Graduação em Linguagem e Ensino, Universidade Federal de Campina Grande/UFCG, \\ Campina Grande, PB, Brasil
}

Resumo: Neste trabalho, apresentamos resultados de pesquisa que tinha em vista responder a seguinte questão: como pensar planejamento de ensino de língua, do ponto de vista de sua constituição como objeto de estudo na formação de professores. O objetivo foi o de propor um esboço de investigação desse objeto, fundamentada em uma revisão bibliográfica sobre ensino e sobre funções de língua e de linguagem. A metodologia utilizada foi específica de pesquisa teórica e consistiu de incursão nas áreas da Didática e da Filosofia da Linguagem e da Linguística para discriminar e relacionar os conceitos fundamentais necessários à definição de planejamento de ensino de língua. Como resultado, o estudo nos possibilitou compreender que os objetivos que orientam um planejamento de ensino de língua são de ordem cognitiva e social, sendo Leitura e Produção Linguística os dois objetos de ensino aos quais se vinculam objetos específicos como referência/referenciação, sentido/significação, expressão/realização e organização linguística.

Palavras-chave: Planejamento de Ensino; Língua Portuguesa; Formação de Professores.

Title: Planning of Portuguese language teaching as an object of study in teacher training

Abstract: In this work, we present research results in which should have answered the following question: how should we think about language lesson planning, according to its constitution as a study object on teacher training. The aim was to propose an investigation overview of its object, based on a bibliographic review about teaching and about language function. The methodology was specific of theoretical research, and consisted of incursion in the areas of Teaching, Philosophy of Language, and Linguistics, in order to distinguish and relate the necessary fundamental concepts to the definition of planning in language teaching. As results, this study enabled us to understand that the aims which guide a language teaching planning are considered cognitive and social. Besides, Reading and Linguistic Production are the two teaching objects in which specific objects are attached, such as reference/referencing, meaning/significance, expression/linguistic accomplishment and organization.

Keywords: Teacher planning; Portuguese Language; Teachers' training.

\footnotetext{
${ }^{1}$ Doutor em Linguística Aplicada (UNICAMP), Professor Titular de Língua Portuguesa e Linguística da Unidade Acadêmica de Letras e Professor Permanente do Programa de Pós-Graduação em Linguagem e Ensino - UFCG. Orcid: https://orcid.org/0000-0001-8641-3225

E-mail: eluizrafael@gmail.com
} 


\section{Introdução}

A formação de professores de língua portuguesa, em foco neste trabalho, é a que se realiza nos Cursos de Letras, como instância acadêmica de formação de profissionais em nível superior. Como resultado da formação nessa instância, é esperado que os alunos egressos desses cursos estejam preparados, na condição social de professores, para desenvolver a ação de ensinar, para enfrentar as dificuldades próprias da realidade local onde vierem atuar e para gerar os benefícios, socialmente, esperados por sua atuação. Seguindo uma organização sistemática disciplinar, o destino de atuação será um lugar ao que ainda se denomina de Língua Portuguesa, como disciplina que, oficialmente, burocrática e institucionalmente, aloca o profissional que se apresentará como professor advindo dessa formação. Para o encaminhamento do que apresentaremos adiante, julgamos como importante destacar, desse contexto inicial, os dois componentes fundamentais professores e língua (portuguesa) - de um processo - formação.

A relação entre esses dois componentes na constituição do processo de formação na instância acadêmica, tal como ainda se apresenta do ponto de vista curricular, é fortemente marcada por duas tendências. Uma de natureza especializada e outra de natureza aplicacionista. Com a introdução dos estudos da Linguística e, em sequência, das diversas disciplinas inscritas nessa área ${ }^{2}$, como componente curricular obrigatório nos cursos de Letras, no Brasil, (SOARES, 2000; DORNELLES, 2012), passa a ser predominante uma formação de especialista em Linguística na perspectiva de estudos descritivos (Linguista de Texto, Analista de Discurso, Sociolinguista, por exemplo). A partir da década de oitenta do século vinte, introduzem-se, de forma periférica, não disciplinar/curricular, propostas, formuladas por linguistas (hoje consideradas importantes contribuições), de mudança do objeto de ensino - da frase para o texto, associadas a novas discussões sobre ensino, advindas da área da Educação. Esse movimento de mudança geraria uma vasta produção acadêmica que muito contribuiu para a formação de professores de língua portuguesa. Assim, passamos a conviver com duas preocupações para a formação do licenciando em Letras (no caso aqui em foco, Língua Portuguesa). Manter a formação especializada e habilitar à aplicação de conhecimentos linguísticos, advindos de diversas disciplinas teóricas, para resolução de problemas de ensino.

A partir de 2002, os cursos de Licenciatura começam a lidar com a necessidade de atender às Diretrizes Curriculares Nacionais, no tocante à articulação entre conhecimentos científicos e didáticos, na formação de professores. Conforme propõem as Diretrizes, os princípios, fundamentos e procedimentos a serem observados na organização institucional e curricular de cada estabelecimento de ensino devem contemplar: a construção de conhecimentos, habilidades e valores em interação com a realidade; a formação de

\footnotetext{
${ }^{2}$ Sociolinguística, Psicolinguística, Linguística Textual, Pragmática, Análise do Discurso e Linguística Aplicada, entre outras.
} 
competências; o princípio metodológico geral da ação-reflexão-ação; a formação geral e profissional; a interação sistêmica com as escolas da educação básica e a organização da matriz curricular em eixos.

Como docente formador de um curso de licenciatura em Letras - Português, de uma instituição federal do interior do Estado da Paraíba, vimos enfrentando o desafio de minimizar o distanciamento entre o estudo da descrição linguística e o estudo da língua como objeto de ensino escolar. Seguindo, supostamente de forma hegemônica, essa forma de pensar, começou a funcionar, nesse curso, a partir de 2011, Projeto Pedagógico, cuja matriz curricular está organizada em eixos. O eixo Docente corresponde a um conjunto de disciplinas que focam a prática de ensino como componente curricular, compreendendo formação e atuação como interdependentes. Conforme proposto no projeto, os professores formadores deverão promover a articulação entre a base teórica do eixo Especialista (Fundamentos de Linguística, Teorias de Leitura e de Escrita, Textualidade e Discurso, Semântica, Fonética e Fonologia, Morfologia e Sintaxe) e o que o projeto denomina de "conhecimentos relativos ao ensino de língua" (UFCG, 2011, p. 18). Para compor o eixo Docente, foram criadas as disciplinas Políticas da Educação, Fundamentos da Prática Educativa, Paradigmas de Ensino, Planejamento e Avaliação.

As disciplinas Fundamentos da Prática Educativa, Paradigmas de Ensino e Planejamento e Avaliação seriam ministradas por docentes do próprio curso de licenciatura. $\mathrm{O}$ argumento fundamental para essa ação foi a ideia de que a orientação para a formação em docência ocorre de forma mais produtiva quando feita por docentes especialistas na disciplina da especialidade de ensino (nesse caso, para Língua Portuguesa, docentes formadores com formação em Letras/Linguística/Língua Portuguesa), o que não ocorreria com a orientação acadêmica advinda exclusivamente da área da Educação.

A preocupação com a ausência de especialista na matéria está relacionada ao temor por uma orientação cuja tendência pudesse ser ou muito generalista (foco apenas em aspectos políticos, sociológicos e filosóficos) ou muito técnica (foco apenas na elaboração de planos de aula, por exemplo.). A nosso ver, e dada a nossa experiência ${ }^{3}$, essa forma de conduzir, embora pareça, aos formadores e aos formandos, mais produtiva porque o objeto de ensino (a língua) estaria em foco, carece, de apoio teórico, na área de Letras, para discriminar, de forma clara, os componentes de um planejamento de ensino de língua. Dito de outro modo, falta-nos sistematizar conhecimento teórico para definir e caracterizar o que é e o compõem um planejamento de ensino de língua. Assim, a questão que nos guiou foi4: como pensar planejamento de ensino de língua, do ponto de vista de sua constituição como

\footnotetext{
3 Assumimos, por cinco semestres letivos seguidos, no período de 2012 a 2015 a disciplina Planejamento e Avaliação.

${ }^{4} \mathrm{O}$ estudo dessa questão fez parte do Projeto de Pesquisa $A$ construção de conhecimento sobre ensino de Língua Portuguesa na área dos estudos da Linguagem, desenvolvido como estágio de pósdoutorado, realizado de maio de 2017 a abril de 2018, no Programa de Pós-Graduação em Educação da Universidade Federal de Pernambuco, sob supervisão da Profa Telma Ferraz Leal.
} 
objeto de estudo na formação de professores? Seria possível pensar como um objeto epistemológico relativamente autônomo à semelhança dos objetos da especialidade?

Tendo em vista apresentar uma proposta de estudo para essa questão, organizamos um possível caminho para sua resposta em três tópicos: necessidade de situar planejamento de ensino de língua como objeto de estudo, especificação dos princípios a serem considerados em toda e qualquer situação de planejamento de ensino de língua e discriminação dos seus componentes fundamentais.

Esse caminho nos permitiu organizar o presente artigo em três partes. Na primeira parte, descrevemos o processo de construção da pesquisa teórica por incursão nas áreas da Didática, da Filosofia da Linguagem e da Linguística. Apoiamo-nos, inicialmente, na concepção de prática social para definir planejamento de ensino, para, em seguida, trazer à reflexão as concepções de ensino e de língua, a partir da qual pudemos perceber as relações entre o ser humano, na condição de professor ou aluno, e o objeto de estudo/ensino. $\mathrm{Na}$ segunda parte, apresentamos uma caracterização de planejamento de ensino de língua, a partir dos estudos de Didática, considerando os princípios norteadores de toda e qualquer situação de planejamento. Na terceira, e última, parte, definimos planejamento de ensino de língua, com base na relação entre os princípios didáticos norteadores e a natureza da linguagem e as características de especificidade da língua.

\section{Sobre o encaminhamento teórico-analítico da proposta de pesquisa}

O encaminhamento teórico-analítico caracteriza o presente trabalho como uma investigação em Linguística Aplicada por duas razões. Primeiro, porque considero planejamento como um fenômeno de linguagem produzido por sujeitos situados sócio historicamente, em vista de atender a determinadas necessidades humanas por meio de suas ações, e não, apenas, como técnica de elaboração de documentos. Segundo, situo planejamento, de um ponto de vista contemporâneo, dentro dos estudos sobre ensino, como prática social. Nesse sentido, os aspectos técnicos e metodológicos (elaboração de planos, seleção e elaboração de materiais e de atividades e aplicação de instrumentos de avaliação) estarão necessariamente atrelados a um conhecimento da realidade social mais ampla e dirigidos a um contexto local (uma região, uma escola, uma turma). Daí, portanto, a necessidade de conhecimento mais especializado sobre a construção da especificidade do objeto de ensino, como parte do processo de planejar, a partir das orientações acadêmicas que constituem parte importante de um sistema, as quais estarão, explícita ou implicitamente, guiando as orientações de natureza oficiais, que se materializam como manuais, guias, parâmetros, diretrizes ou programas curriculares.

Como exemplos da produção acadêmica brasileira, fazemos menção a duas obras de divulgação de conhecimentos científicos sobre língua/linguagem e sobre ensino de língua, cujas publicação e divulgação podem ser consideradas de forte impacto para uma mudança 
paradigmática e uma suposta consolidação do que passaria a se pensar língua como objeto de ensino, no Brasil, principalmente, a partir dos anos oitenta do século passado. A escolha por essas obras como material ilustrativo da produção acadêmica se justifica por serem os legítimos representantes de uma instância responsável por produzir orientações que sinalizariam modos de pensar determinados objetos e objetivos de ensino, tendo em vista contribuir para o processo formal educativo para a formação humana, o que, em nosso caso, se realizaria pelo pleno exercício das capacidades e habilidades de uso linguístico dos seres humanos em atuação social.

Do lugar de sua produção, as orientações acadêmicas são produzidas por especialistas em estudos linguísticos e exerceriam impacto e efeitos na forma de conceber a língua como objeto de ensino na Educação Básica. Essas orientações chegam à formação de professor, via cursos de licenciatura, como conteúdo curricular paralelo a conteúdos específicos de descrição linguística (Fonética/Fonologia, Morfologia e Sintaxe) e das diversas especialidades de estudos linguísticos (Sociolinguística - principalmente, a Variacionista -, Linguística Textual, Análise do Discurso, Pragmática, Psicolinguística, entre outras). Tem se acreditado ser possível equacionar essa relação com a prática de análise linguística.

As obras de divulgação, tomadas neste trabalho como exemplares, são, a nosso ver, representativas de dois importantes momentos de apresentação às instâncias da formação acadêmica e da atuação de professores de língua portuguesa, em nosso país, da língua como objeto de ensino de modo diferente e em substituição ao modelo tradicional para o qual língua é apenas conjunto de regras normativas e seu ensino seria, então, realizado pela mera exposição a esse conhecimento. São elas: $O$ texto na sala de aula: leitura \& produção (GERALDI, 1984) e Gêneros orais e escritos na escola (SCHNEUWLY, DOLZ, 2004). As duas obras, situadas historicamente em momentos distintos (duas décadas entre as publicações), têm em comum a ideia de ensino de língua centrado no estudo do "texto" como lugar de manifestação dos usos linguísticos. Para a primeira, a grande motivação foi a necessidade de se propor um ensino de língua mais produtivo do que o ensino centrado exclusivamente na memorização de regras gramaticais. Para a segunda, foi a necessidade de ampliação do conceito de "texto" como objeto de ensino, sob a denominação de "gêneros textuais ou gêneros discursivos", na expectativa de contemplar a diversidade textual própria da realização linguística, escrita e oral. Quando aproximamos as duas obras, em relação à centralidade do objeto de ensino, não estamos afirmando adotarem os seus autores o mesmo sentido ou conceito para "texto" nem equivalência entre "texto" e gênero", mas ressaltando o fato, importante, de as duas produções sinalizarem, em épocas e contextos distintos de produção, para a principal mudança paradigmática, qual seja a de tomar como material empírico a ser objeto para atividades de ensino de leitura, de produção textual e de análise linguística o produto das interações ou interlocuções humanas: algo para além de uma sequência de itens linguísticos descolados do mundo social e algo que se materializa de 
uma determinada forma (quando preciso "avisar", produzo um "aviso", não uma "solicitação"). ${ }^{5}$

De natureza formal, instâncias como o Ministério da Educação ou as Secretarias Estaduais de Educação, para o caso de nosso país, a quem compete fazer existir e garantir o funcionamento de certos produtos de linguagem veiculadores de normas ou diretrizes, destinam seus produtos às escolas, como última instância, a quem compete atender às demandas que o mundo a ela externo estiver dirigindo aos seres humanos na condição de agentes sociais. Às universidades está destinada a função de produzir conhecimento especializado e de propor alternativas para solução dos problemas sociais, inclusive os relativos a ensino. As duas obras, às quais me refiro como exemplares de uma vasta produção brasileira desse intento, representaram e ainda mantêm sua posição em relação a essa função ${ }^{6}$. Não é raro ouvirmos que a escola precisa estar "antenada" com o tempo e o lugar e que os cursos de formação de professor precisam ser menos teóricos ou ser capazes de formar profissionais que transitem entre teoria e prática com efetiva desenvoltura, além de muitas outras reclamações quanto a essa relação de dependência. Nesse sentido, os produtos gerados por essas instâncias serviriam como uma espécie de catalisadores das expectativas a serem atendidas e mediadores entre sociedade e escolas.

\footnotetext{
${ }^{5}$ Geraldi (op. cit., p. 77), para propor que o ensino deva possibilitar o domínio efetivo da língua em suas modalidades oral e escrita, toma por base o postulado de que saber a língua é dominar as habilidades de uso em situações concretas de interação, entendendo e produzindo enunciados adequados aos diversos contextos. Dolz, Noverraz, Schneuwly (2004, p. 82-84), para apresentar o procedimento denominado de "sequência didática", partem de princípios teóricos, segundo os quais "os textos escritos ou orais que produzimos diferenciam-se uns dos outros porque são produzidos em condições diferentes", mas, em situações semelhantes apresentam características semelhantes, constituindo, assim o que denominam de gêneros de textos. Segundo os autores suíços, nessa perspectiva, o ensino de língua deve ter a finalidade de ajudar o aluno a "dominar melhor um gênero de 'texto', permitindo-lhe, assim, escrever ou falar de maneira mais adequada uma dada situação de comunicação. Não podemos, é claro!, afirmar haver uma correspondência conceitual absoluta, mas, a presença do material verbal "texto" em lugar de "frase" e este como objeto da produção linguística humana é evidente em ambos.

${ }^{6}$ Para comprovar o que afirmamos, é possível ao leitor verificar a recorrente referência a Geraldi (1984), quando se pretende remeter ao histórico da presença do conceito de texto e concepções de linguagens para situar mudanças da perspectiva de ensino do prescritivo para o reflexivo, bem como a profusão, pós divulgação da obra de Schneuwly e Dolz (2004), no Brasil, de relatos de experiência de ensino e de descrição de sequências de ensino (inspiradas nas sequências didáticas), nas formas de apresentação de trabalho em eventos, textos em anais, artigos em periódicos, monografias, dissertações de mestrado e, até, teses. Além da produção exclusivamente acadêmica, ainda se pode contar com a, igualmente pródiga, produção do mercado editorial, na forma de livros. A produção apoiada no estudo desenvolvido a partir da segunda obra tem como principal eixo teórico norteador o que se divulgou em nosso país como Interacionismo Sócio Discursivo. Não é nosso objetivo analisar essa produção aqui. Apenas apontar a sua existência, do ponto de vista teórico, como um importante componente do processo de planejamento de ensino. No entanto, o que nos interessa, aqui, é uma tentativa de sistematização teórica desse componente menos comprometida com uma ou outra corrente ou área de estudos e mais centrada em princípios dos dois objetos fundamentais do processo de planejamento: nesse caso, língua/linguagem e ensino.
} 
No entanto, as relações entre os produtos de nossas ações, geradas por recolocações em situações diversas de uso, nem sempre se mostram nitidamente na duração de nosso agir. Uma explicação para esse fato pode ser do ponto de vista sociológico. Como elaboradas formas de organização social (GIDDENS, [1984]2009) podemos compreender as instituições formais, entre elas, a escola, nas quais indivíduos interagem fisicamente, via de regra, de modo presencial, em contextos situados de interação. No entanto, para o funcionamento do sistema escolar, outras instâncias, também com rotinas e agentes próprios, exercem, direta ou indiretamente, certos tipos de influência. Basta, para isso, que se pense, por exemplo, na expectativa criada com a aplicação de instrumentos como Prova Brasil ou com a divulgação e classificação da qualidade das escolas a partir dos resultados do Índice de Desenvolvimento da Educação Básica (IDEB) ou, ainda, com a divulgação dos estudos sobre linguagem e seus usos, como ocorreu, no Brasil, com os estudos sobre textualidade sob a denominação de gêneros textuais ou sobre ensino de língua carreados pela expressão genérica "sequência didática".

Essa base conceitual do modo de organização da vida social nos fornece, no caso aqui em foco, os caracteres necessários para o que consideramos como planejamento de ensino enquanto prática social: uma rotina situada de interação, em que os seres humanos, na condição de agentes específicos, fazem funcionar modos estabelecidos de atender a determinadas finalidades. Assim, o que lhe é próprio ao funcionamento se mantém nos limites de sua rotina. Talvez, por isso, e por ser de ordem externa à escola e à sua rotina imediata de funcionamento, a presença das instâncias externas à sala de aula (a das orientações oficiais e das orientações acadêmicas) seja de difícil visibilidade. Acreditamos não ser de todo improvável afirmar que, por exemplo, documentos como PCN, e, mais recentemente, a Base Nacional Comum Curricular (BNCC), não sejam objeto de estudo sistemático em reunião de planejamentos nas escolas da educação básica e em cursos de formação e professores em nosso país. Por outro lado, é possível afirmar haver uma crença generalizada nos efeitos positivos da aplicação de conhecimentos científicos, a exemplo do que ocorre, nas últimas décadas, com os conceitos de gêneros textuais, em substituição a texto, e de sequência didática, em substituição a plano de aula, advindos do discurso da divulgação veiculado por obras acadêmicas; em sua maioria, na forma de livros, produtos do mercado editorial.

Para construção do percurso de investigação teórica desse trabalho, tomo as concepções de prática social, por um viés sociológico (GIDDENS, [1984]2009), de ensino como prática social e de seus elementos constituintes (SACRISTÁN, GÓMEZ, 1998; ZABALA, 1998; CHARLOT, 2000; SAVIANI, 2010; PIMENTA, 2011; LIBANEO, 2011, 2013; LUCKESI, 2011) e de língua/linguagem como objeto de estudo (FRANCHI, 1992; BORGES NETO, 2004; CASTILHO, 2010). A partir dessas concepções, recortamos os conceitos de agentes, ações, meios e condições, relativas a prática e a ensino, e o de uso linguístico, referente a língua/linguagem. Acredito que será na articulação desses dois eixos: ensino como prática social e uso de língua/linguagem, que melhor discriminaremos os princípios e componentes 
de todo e qualquer planejamento de ensino, aqui considerado como a fase complementar do ensino que se materializa nas situações concretas em sala de aula, de modo presencial ou não. Assim, o percurso que proponho para essa reflexão é, basicamente, articular conhecimentos advindos da Didática, especificamente, do que se pode denominar de Didática Específica ou Didática de Conteúdos, o que, para nosso caso, pode também ser denominado de Didática de Língua ou Didática do Português com conhecimentos da Filosofia, Filosofia da Linguística/Linguagem e da Linguística. Da Didática, interessa-nos buscar as categorias que compõem o processo de ensino, as quais todo e qualquer planejamento deve contemplar. Da Linguística, interessa-nos destacar a percepção da língua como objeto que pode ser ensinado, a partir de uma tentativa de compreender esse objeto entre a percepção genérica e abstrata típica da teoria linguística e a específica e concreta dos usos situados, conforme direção apontada pela Filosofia da Linguagem e da Linguística (DELEUZE, [1969]2000; AUROUX, 1998; FRANCHI, [1977]1992; BORGES NETO, 2004; CASTILHO, 2010; RAJAGOPALAN, 2003, 2008), tendo por base a questão filosófica da função da língua e da linguagem, como princípio fundamental que deveria reger as ações de planejar ensino.

Nesse ponto, vale ressaltar o sentido com que me refiro a função, para a proposta de reflexão, neste trabalho. Como nos lembra Martelotta (2009), precisar uma definição para função, em Linguística, é uma tarefa difícil, dada a natureza abstrata e complexa do objeto que responderia à pergunta: qual a função ou funções da linguagem e das línguas naturais? Qualquer rápida revisão por manuais de Linguística nos colocará diante de sentidos como comunicação, intenção, interação, entre outros, para explicar o que o ser humano faz ao utilizar a linguagem e uma dada língua natural. Não nos interessa, nesse caso, estender e aprofundar essa discussão, mas apenas ressaltar o que é relevante para pensar planejamento de ensino de língua, de um modo teórico, destacando seus princípios fundamentais. Não há como chegar a essa especificação sem que tenhamos o mais claro possível respostas para por que ou para que usamos linguagem e língua?, o que seria justificativa para a resposta de questões pertinentes para a proposta do presente trabalho: por que o ser humano precisa aprender a usar linguagem e língua?, o que o ser humano precisa aprender de linguagem e de língua, na escola? e, por consequência, por que precisamos ensinar, aprender a ensinar, planejar o que será ensinado e saber o que é e como planejar ensino de língua?

Ora, relacionando essas questões à expectativa da ação de ensinar, desta também se espera alguma função, que sirva para atender a alguma necessidade do ser humano. Assim, o ponto de encontro aqui é a função: do objeto e da instituição mediadora; linguagem, língua e a escola (ensino). Para isso, será pertinente a noção de função da linguagem, conforme sentido apresentado por Franchi ([1977]1992) ${ }^{7}$, em texto clássico sobre o assunto,

\footnotetext{
7 Seguramente, em recentes manuais de linguística, podemos encontrar essa noção muito bem desenvolvida por outros autores. Nossa opção, neste trabalho, foi tentar manter a referência mais
} 
no Brasil, e partilhado sob muitas e diversas formulações após sua publicação. Para o autor, a linguagem, antes de ser mero instrumento de comunicação e de interação, é, ela mesma, um processo de construção do pensamento, criador, transformador e organizador de nossas experiências. Acreditamos ser esse ponto teórico muito importante para pensar metodologicamente qualquer investigação que se pretenda a respeito de planejamento de ensino de língua porque sempre estaremos na dependência de uma concepção de linguagem. Seguindo Franchi ([1977]1992), é importante ressaltar que a atividade linguística, aqui compreendida como a realização pelo ser humano de uma língua natural em situação de linguagem, envolve, necessariamente, a realização de operações interiores ao sujeito que se manifestam na materialização do sistema linguístico (fonético, morfológico, sintático) e de operações que tenham em vista a realização de funções sociais exteriores ao sujeito.

Assim, para os propósitos do presente trabalho, para pensarmos sobre linguagem/língua como objeto de planejamento de ensino, téorica-metodologicamente, a reflexão que se seguirá terá como apoio essa concepção de língua e linguagem, da qual se depreendem as importantes relações entre o ser humano, na condição de professor ou aluno, e o objeto de estudo/ensino: da relação interna, entre o sujeito e o material linguístico, e da relação externa, entre o sujeito e as condições sociais que fazem funcionar o material linguístico.

\section{Caracterizando planejamento de ensino de língua como objeto de estudo}

Nosso intento é propor um caminho de pensar planejamento de ensino de língua com relativa autonomia, do ponto de vista acadêmico-científico, uma vez que, epistemologicamente e institucionalmente, o lugar de estudo da ação de planejar ensino é a área da Educação e da Pedagogia, tendo como campo específico a Didática, ao qual, por último, cabe, a investigação da constituição do processo de ensinar. Independentemente do lugar teórico ou institucional de observação, é preciso considerar que a ação de planejar se movimenta sempre em relação a uma outra ação e esta a um objeto sobre o qual recai o resultado esperado ou o atendimento a um objetivo esperado, tendo como expectativa atender a uma necessidade: planejo economizar dinheiro, viajar nas férias, manter uma vida saudável, entre muitas outras que organizam a vida humana individual ou coletivamente. Em relação a ensinar, de modo geral, o movimento é o mesmo: alguém planeja ensinar algo a outro alguém.

De início, já poderíamos supor e, até afirmar não ser um objeto, nem epistemológico, nem institucional, nem disciplinar, da área de conhecimento Letras e/ou Linguística, ou de Estudos da Linguagem. Se observarmos a relação entre as expressões nominais, por outro caminho, chegaremos à mesma possibilidade de sentido: língua portuguesa está ordenado 
por planejamento de ensino. Assim, parece estarmos tratando de um objeto alheio, se considerarmos nossa filiação institucional de formação e de atuação. É possível, então, do lugar institucional do qual falamos - Letras, Linguística, Linguística Aplicada - dizermos o que é tal objeto, como se constitui e se realiza? Quais são os problemas específicos do planejamento de ensino de língua portuguesa? Olhando desse lugar, há condições epistemológicas, metodológicas e práticas para investigações que auxiliem na elucidação da natureza desses problemas e na proposição de alternativas de enfrentamento em busca de soluções? Essa estranheza pode se acentuar se aceitamos que planejar ensino é uma ação do processo formativo de seres humanos a que, genericamente, podemos denominar de educativo (LIBÂNEO, 2011). Assim, como resultado de um olhar talvez aligeirado e genérico, podemos afirmar não ser um problema epistemológico para os Estudos da Linguagem, que, historicamente, no Brasil, tem Letras e Linguística como áreas representativas: a estas, sim, caberia o estudo da descrição da forma e do uso das línguas ditas naturais, de modo mais restrito, ou de modo mais amplo, das implicações e efeitos para e na construção dos sujeitos e de suas ações mediadas pela linguagem verbal.

Desenvolveremos este percurso teórico, considerando planejamento de ensino de língua portuguesa na educação básica como uma expressão definidora de natureza referencial, uma vez que, quando enunciada, nos remete, cognitiva e historicamente, a algo de um mundo conhecido e, por isso, assim, nomeado. Como uma espécie de relação de supra ordenação, são percebidos dois grandes componentes ou eixos de conhecimentos: a educação e a língua, aos quais se interligam os demais: ensino, básica e planejamento; referentes a educação, e portuguesa; a língua. Desse modo, tendo em vista a reflexão que pretendemos desenvolver, fazemos a seguir uma breve revisão do conceito de ensino para depreender aspectos necessários ao estudo de planejamento.

O primeiro ponto teórico a ser considerado é a concepção de educação como um processo de formação, intencional ou não, dos indivíduos para participação ativa e transformadora nas várias instâncias da vida social, a realizar-se por meio da assimilação, da apropriação, da reprodução, da sistematização e da renovação de conhecimentos, experiências, valores, crenças, modos de agir, técnicas e costumes. Em sentido restrito, a educação intencional é a que se realiza a partir de objetivos definidos por fins e exigências sociais, políticas e ideológicas. Dentre as instituições às quais cabe desenvolver processos dessa natureza (igrejas, empresas, sindicatos), em nossa sociedade, a escola ainda é a principal agência que possibilita, conforme nos lembra Libâneo (2013), por meio do processo de escolarização básica, prover os indivíduos dos conhecimentos científicos e técnicos necessários para atuação; inclusive, em outras instituições.

A esse processo de natureza formal e intencional, quando posto em ação, denominase ensino. Assim, como ponto de partida, é preciso considerar também ensino como um processo intencional (LIBÂNEO, 2013; LUCKESI, 2011) porque faz realizar objetivos previamente determinados, mesmo que não estejam explicitamente dados na situação concreta de sala de aula. Como uma intenção, precisa se materializar no mundo físico, o que 
requererá dos envolvidos a realização de ações. Porém, essas ações não podem ser aleatórias porque se tem em vista um determinado objetivo ou finalidade ou meta a serem alcançados. A realização dessa intenção precisa ser, então, operada de forma sistemática, obedecendo a uma sequência de ações que se desenvolvem durante tempos determinados e por agentes também determinados (professor e alunos). A cada conjunto de ações interligadas teremos atividades propulsionadas por um objetivo, visando a atingir a uma meta ou uma finalidade.

Voltamos, desse modo, à mola propulsora de todo o processo: o objetivo. O objetivo de ensino é, de início e por fim, o que caracterizará a situação como didática porque guiará a definição do objeto a ser ensinado (de modo geral, o conteúdo de ensino), a elaboração das atividades, a seleção dos materiais e os instrumentos de avaliação. Mais do que qualquer outro componente do processo de ensinar, é o que representa a intenção formativa que se tem em mira. Se se pretende formar leitores capazes de distinguir fatos de opiniões, por exemplo, essa pretensão estará ancorada em um objetivo mais amplo que pretende contribuir para a formação de um leitor proficiente em uma determinada língua.

A questão é que, por ser intencional, formal e institucional, o ensino tem seus objetivos previamente determinados aos planejamentos. Dito de outro modo, formar um leitor é um bem comum a todos e, por isso, é um objetivo que deve estar posto como uma finalidade de caráter formativa. A atividade que exercita a capacidade de distinguir fatos de opiniões, por exemplo, será um instrumento para que se desenvolva essa formação, desencadeando, desse modo, um processo que articula instrução, fins imediatos (ensinar a distinguir $X$ de $Y$, aprender que $X$ é diferente de $Y$ ) com formação, fins mediatos (saber a diferença entre $X$ e $Y$ media a formação do leitor). A predeterminação de tais objetivos está prevista em duas importantes instâncias: a dos programas oficiais, do Ministério da Educação até os Projetos Pedagógicos das Escolas, por meio de documentos parametrizadores e da divulgação de conhecimentos científicos especializados sobre o objeto a que dado objetivo se refira (por exemplo, leitura), por meio de artigos, livros, palestras, e de outros gêneros produzidos por especialistas, em nosso caso da área de Letras e de Linguística, que cumprem a função social de divulgar não apenas modos de conceber tal objeto mas também de propor formas de inserção de novos conhecimentos para a renovação das práticas de ensino. Outra questão importante também, que se manifesta já como uma situação prévia de planejamento, é o fato de os documentos parametrizadores deverem ser ancorados em um pensamento teórico ou em modelos teóricos de análise do fenômeno a ser ensinado. O que estamos salientando é a necessária relação entre pensamento teórico e planejamento, mas não a neutralidade dessa relação do ponto de vista da elaboração de documentos parametrizadores, nem negligenciando as tensões a que toda situação de planejar e executar ações do processo de ensinar se submete. 
Dados os limites e os interesses do presente trabalho, fazemos um recorte para focar um componente desse processo: o conteúdo ou o objeto de ensino ${ }^{8}$. Com base nas contribuições de Saviani (2010), retomamos a ideia de resgate do processo de constituição dos conhecimentos científicos no ensino dos conteúdos escolares, para focar "planejamento de ensino de língua" como objeto de estudo na formação docente, construído na relação entre o conhecimento específico sobre língua/linguagem e o conhecimento específico sobre ensino. Por isso, não exploraremos os outros componentes: atividades, materiais e instrumentos de avaliação, nem as condições sócio-político e históricas de realização do ensino.

Para tratamento desse componente, é importante ainda considerar que ensino deve ser compreendido como prática social, para além dos limites da aprendizagem que ocorre na tríade professor, aluno e conteúdo, de inspiração comportamentalista, humanista ou construtivista. A compreensão é de uma prática social concreta (OLIVEIRA, 2011) que ocorre de forma articulada a outras práticas (por exemplo, a elaboração das diretrizes oficiais, a divulgação científica e os projetos pedagógicos), tendo em vista a formação social do país. Nesse caso, assumem-se posições contraditórias ou mediadoras, visando à transformação de relações sociais (exploração e dominação, por exemplo). Assim, procura-se construir explicações de realidades de ensino em salas de aula do ponto de vista de suas relações com o sistema educacional e com o sistema social mais amplo. É uma prática social porque atende a necessidades, funções e determinações que estão para além das intenções e previsões dos agentes diretamente envolvidos na situação concreta de aula. $E$, em qualquer de suas fases, planejar ensino é, igualmente, uma prática social porque é ação dirigida por alguém para atender a necessidades, funções e determinações que pertencem a esses sistemas.

Esse modo de ver, sociologicamente orientado, apoia uma importante tendência, para a formação e atuação docentes, especialmente quanto a como compreender planejamento de ensino. Em nossa área, as elaborações de sequências didáticas à semelhança de modelos importados são exemplos de formas de ensinar a planejar a partir de modelos a priori, resultando, de modo geral, em planos de aula descolados da vida social, apenas. É imprescindível o conhecimento da realidade educacional e do ensino, buscando compreendê-la e problematizá-la. Dito de outro modo, planejamento de ensino socialmente situado é o que tem em vista atender às necessidades de realidades particulares, de modo atrelado ao que está proposto como diretriz de ordem geral. Isso não significa gerar atitudes de passividade. Por isso, é preciso compreender o que está posto como planejamento de ordem externa à sala de aula, via de regra manifesto em orientações oficiais e acadêmicas.

Nesse caminho, destacamos sentido apresentado por Luckesi (2011, p. 165) para planejamento de ensino como o "um ato decisório político, científico e técnico". É político porque estabelece uma finalidade intencionalmente construída, de natureza abrangente e depende de uma posição ou decisão filosófico-ideológica. É uma decisão que direciona o

\footnotetext{
${ }^{8}$ Conforme Zabala (1998) e Sacristán e Gómez (1998), sobre conteúdos.
} 
conjunto de ações vindouras. É científico porque necessita apoiar-se em conhecimentos científicos que garantem uma possibilidade de conexão objetiva com a realidade a ser exposta como objeto de ensino (em nosso caso, a língua e os fenômenos que a constituem e a fazem funcionar). É técnico porque necessita construir modos de operação que mediam a decisão política e a compreensão científica do processo total. Desse modo, como lembra o autor, planejamento de ensino não é um ato de preenchimento de formulários e nem, acrescentamos, apenas sessões de discussões sobre problemas sem tomada de decisões e sem registro, ou cópias de planos apoiados exclusivamente na perspectiva acadêmicocientífica. É, exatamente, nesse ponto, que direcionamos nosso olhar para situar planejamento de ensino de língua em função dos dois componentes fundamentais de um processo formal e institucional: os objetivos e o conteúdo ou o objeto de ensino.

Como já dito, os objetivos são a mola propulsora. Deles se parte e a eles se volta em todo o processo e em toda a ação de planejar. Mas, como dito também, ensina-se algo que se acredita ser fundamental para a formação dos indivíduos. Esse "algo" será, então, o alvo do ato científico a que Luckesi se refere. Por exemplo, não se espera mais que a concepção de leitura que esteja guiando seu ensino seja a de mera decodificação porque essa constatação científica já não é mais suficiente para explicar como os seres humanos leem. De modo semelhante, língua como estrutura, embora continue sendo uma afirmação científica verdadeira, não é suficiente para explicar como os seres humanos produzem e fazem funcionar as mais diversas formas de textos. No entanto, como conteúdo de formação, é parte importante do conhecimento cientificamente produzido sobre língua/linguagem. Não estamos, com isso, afirmando que a construção do currículo do ensino básico se apoie ou deva estar apoiado unicamente no conhecimento científico, tomando-o como homogêneo. Sobre essa questão, lembramos afirmações de Sacristán e Gómez (1998), quanto à dependência da seleção de conteúdos a forças dominantes para cada momento de construção curricular e a valores historicamente delineados. De igual modo, o conhecimento científico não é independente de seus produtores, nem das circunstâncias em que é produzido. Mas, o que acreditamos ser importante destacar é a importância do conjunto de saberes, nesse caso, sobre língua/linguagem, de origem científica para a formação docente e, por consequência, para o estudo de planejamento de ensino.

Desse modo, chegamos a outro momento teórico que é o da consideração do que se ensina, o que se configura, em decorrência do objetivo pretendido, como o segundo componente fundamental do processo de ensino e de qualquer planejamento. Esse ponto está relacionado ao que a Didática classifica como conteúdo, conteúdo escolar, matérias de ensino, currículo específico, a depender do foco que o analista ou o professor necessite em determinada situação. Por exemplo: se a referência for ao currículo da escolarização básica, a tendência, em nosso país, é que predomine a terminologia conteúdo e disciplina - Língua Portuguesa - e o mesmo vale para os cursos de licenciatura (assim: Estágio Supervisionado é uma disciplina que tem um conteúdo $X$ = Linguística é uma disciplina que tem um conteúdo 
X). No caso da formação em cursos de licenciatura, há que se destacar dois tipos de conteúdo: o da especialidade - a Língua e as Literaturas - e o da docência - o Ensino. É, exatamente, nesse ponto, que acreditamos ser urgente situar planejamento de ensino de língua como um conteúdo ou um objeto de estudo, o que será melhor visualizado se considerado como um problema de investigação de Didática Específica.

A determinação do que se tem como conteúdo, de modo semelhante aos objetivos de ensino, também está previamente, embora possa parecer mais relativo, apresentada, de forma explícita ou de forma implícita. Aliás, há quem reclame quando não está. Exemplos formais dessa explicitação são os sumários e as grades de conteúdos em livros didáticos ou as listas distribuídas por direção e coordenação de escolas a professores, geralmente, em início de ano letivo. Implicitamente, além do que se considera como currículo oculto ou currículo vivido (não trataremos aqui), pode ser depreendido a partir dos objetivos que se enunciam nas orientações oficiais e nas propostas das orientações acadêmicas.

Se o que está em estudo ou em investigação é ensino formal, institucional, de caráter instrucional e intencional, conforme já definido, não há como proceder a qualquer planejamento (ou execução em sala de aula) sem que se tenha resposta para a pergunta que complementa o objetivo: o que se ensina, o que se deve ensinar ou o que se espera ser ensinado. Vejamos que a referência agora é a uma substância e não uma finalidade. Esperase ensinar algo. Para designar essa substância, do ponto de vista didático, o termo, historicamente constituído na prática acadêmica, utilizado tem sido conteúdo. Conforme Zabala (1998), esse termo tem sido utilizado para expressar aquilo que deve ser aprendido, mas em relação quase exclusiva aos conhecimentos das matérias ou disciplinas clássicas e, habitualmente, para se referir ao conhecimento encapsulado por nomes, conceitos, princípios, enunciados e teoremas. Para o autor, essa é uma forma restrita de utilização do termo que impede a compreensão da necessária relação entre o objetivo e o objeto de ensino. Quando relacionados a objetivos de ensino, os conteúdos podem ser de diversas naturezas: dados, habilidades, técnicas, atitudes, conceitos, crenças, etc. Essa compreensão apoia-se nos princípios de ensino-aprendizagem, os quais, segundo Coll (2000), dizem respeito às finalidades mesmas do processo: o que se deve saber? (conteúdo conceitual), o que se deve saber fazer? (conteúdo procedimental) e como se deve ser e agir? (conteúdo atitudinal).

Acrescentamos visão apresentada por Saviani (2010) que, ao fazer revisão teórica sobre o assunto, chama a atenção para a importância do conhecimento sistematizado na constituição do conteúdo escolar e por Libâneo (2011) que propõe uma abordagem críticosocial dos conteúdos. Para Saviani, sem desconsiderar a necessária vinculação entre todos os tipos de conteúdos a serem ensinados/aprendidos, por meio de relações inter/multidisciplinares, (conhecimentos, habilidades, hábitos, atitudes, valores, normas), o principal é o representado pelos conhecimentos sistematizados, em geral advindos das Ciências. Estes servem de instrumento a toda e qualquer atividade de ensino em vista do encaminhamento para que se realize determinado objetivo. Voltamos, embora de forma 
breve, ao exemplo de ensino de leitura. Para a formação de um leitor proficiente e crítico, é necessário saber distinguir fato de opinião. Logo, saber o que é fato e o que é opinião é um instrumento a esse serviço. Fato e opinião são transferidos, assim como célula, região geográfica, ortografia etc, para a situação de ensino, pela via do planejamento, como objetos cognoscíveis, que podem ser, cognitivamente, conhecidos e reconhecidos.

Para Libâneo (2011), um processo didático crítico-social constitui-se da assimilação ativa da experiência cultural acumulada, possibilitando ao aluno o domínio de conhecimentos, habilidades, hábitos, convicções, desenvolvimento de capacidades cognocistivas e operativas, por meio da leitura crítica da realidade. Para isso, segundo o autor, é necessário apreender o objeto de conhecimento nas suas propriedades (aqui, aponto para o nosso caso: uso de língua/linguagem e suas propriedades), características, relações, contradições e nexos sociais. Assim, nessa perspectiva, os conteúdos precisam ser situados no mundo em que ocorrem.

Tendo em vista a reflexão que pretendemos apresentar nesse trabalho, fazemos mais um recorte para situar planejamento em relação a conteúdo como componente do processo de ensino. Nesse caso, conteúdo é o que se deve saber sobre "planejar ensino de língua". Assim, planejamento de ensino de língua é "conteúdo ou objeto de estudo da/na formação de professores de língua portuguesa". Nesse sentido, embora não desenvolva com a amplitude necessária nesse artigo, o que apresentamos é parte da discussão sobre formação curricular nos cursos de licenciatura e uma proposta de campo de investigação na relação com os conhecimentos acadêmicos sobre língua/linguagem. O que destacamos aqui como relevante, nesse momento, para caracterizar planejamento de ensino de língua como um objeto ou um conteúdo de estudo na/da formação de professores são os dois componentes fundamentais desse próprio processo de ensinar: os objetivos e os conteúdos, dos quais dependerão os demais: atividades, tarefas, materiais, recursos e instrumentos de avaliação.

Desse modo, chegamos a um lugar de especificidade didática, pois os objetivos e os conteúdos não são de caráter geral, mas se referem a ensino de língua. A partir daqui, são os conhecimentos de ou sobre língua e o que se espera que se saiba fazer quando se age no mundo ou se é atingido no mundo pelos efeitos dos usos desse objeto cognoscível que determinarão as possibilidades de ensino a serem construídas. Requer, portanto, um direcionamento investigativo como didática específica e não apenas uma aplicação de conhecimentos de teorias da Linguística para solução de problemas isolados ou mera exercitação de elaboração de planos de aula descolados da vida social. Pode parecer, à primeira vista, um problema resolvido, se considerarmos que, no Brasil, desde os anos oitenta do século passado, linguistas e linguistas aplicados assumiram a liderança na apresentação de propostas de solução para problemas isolados de ensino da disciplina de língua na educação básica, como superação da chamada "crise da leitura" pela adoção de um modelo psicolinguístico, substituição do ensino tradicional de memorização de regras gramaticais pelo tratamento da variação linguística pelo viés da Sociolinguística Variacionista, substituição do ensino de redação escolar pelo ensino de produção textual a 
partir de categorias de descrição advindas da Linguística Textual, substituição do estudo de vocabulário pelo estudo de sentido a partir de categorias advindas da Análise do Discurso Francesa; apenas, para lembrar os movimentos de maior impacto.

Apesar das indiscutíveis contribuições daí geradas, não se tem na área de Letras, como instância formadora de professores, uma sistematização epistemológica relativamente suficiente para discriminar a especificidade e os componentes do ensino, de modo a se constituir como um conteúdo de formação, independente de uma filiação teórica, mas fazendo emergir o que realmente é específico do objeto disciplinar. Essa tarefa terminou por ser assumida por autores de livros didáticos ou elaboradores de materiais didáticos, o que se pode comprovar por uma, mesmo breve, incursão por manuais ao professor anexos a livros didáticos em circulação no país, onde se apresentam grades de objetivos de ensino para cada ciclo e ano de ensino da educação básica. A nosso ver, a ausência da articulação com o caráter didático do objeto: a língua para fins de ensino, é a principal causa dessa lacuna. Outra razão, apontada por estudiosos da área da Educação e especialistas em Didática e Formação de Professores (FILLOLA, 2003; ANDRÉ, 2011; ALARCÃO, 2011, entre outros), é o ensino de didática cuja tradição tem sido a orientação fortemente instrumental, sem vinculação com uma dada realidade, sem referência aos fins e às teorias de fundamentação; aí incluídos os conhecimentos específicos de referência a partir dos quais deveriam ser depreendidos os possíveis ou os esperados objetivos de ensino de uma língua, para falantes/usuários nativos, assim como os conteúdos relevantes e pertinentes para o alcance desses objetivos.

Caracterizando, pois, planejamento de ensino de língua portuguesa como um objeto de estudo na/da formação de professores, conforme percurso construído nesta reflexão, propomos focar os princípios norteadores de toda e qualquer situação de planejamento, quais sejam: a especificidade a partir das categorias fundamentais do ensino que são os objetivos e os conteúdos.

\section{Pensando planejamento de ensino de língua a partir da especificidade do objeto}

Ensinar se constituiu, ao longo do tempo da formação da sociedade, em suas formas tais como conhecemos hoje, uma necessidade social porque, como nos lembra Charlot, com apoio da Filosofia, (2000, p. 53), ao nascer, o ser humano "entra na história maior da espécie humana" e, assim, se inscreve como sujeito dessa mesma história, vindo a participar do conjunto de relações e interações com outros, a ocupar lugares físicos e sociais e a exercer determinadas atividades. Para se constituir sujeito, o ser humano precisa aprender para apropriar-se do mundo e de sua história, por meio das relações entre os outros, sabendo reconhecer e se utilizar de processos que constituem sistemas de sentido que nos dizem quem somos, o que/quem é o mundo, quem são os outros, por que somos, como ou o que poderia (ríamos) ser etc. O conjunto, então, do que se sabe e do que se guardou 
historicamente a esse respeito pode ser denominado de conhecimentos, aos quais os seres humanos em formação precisam ter acesso, compreendê-los, utilizá-los e (re)produzi-los em novas experiências de vida.

Como sabemos, um dos importantes conhecimentos, para a construção da história e da própria constituição do ser humano como sujeito é o que se sabe sobre linguagem, em sentido amplo, como faculdade humana de expressão verbal, sobre língua, em sentido estrito, como sistema organizado de unidades fonológicas, morfológicas e sintáticas, circunscritos histórico e geograficamente, a que, de modo genérico e superficialmente, denominam-se línguas naturais, oficiais ou idiomas: português, inglês, francês, espanhol etc., e sobre seus usos e implicações desses usos na constituição do próprio sujeito. Aqui, importa fazermos uma distinção entre dois conjuntos ou duas formas de construção e de manifestação desse conhecimento: o que se ensina e se aprende de modo naturalizado, espontâneo, em situações cotidianas da interação humana, e o que se aprende e se ensina de modo controlado, regrado, em situações formais de ensino, dentre estas, a escolar.

Nesse ponto, destacamos, assim, um conjunto particular de conhecimento, como produto do olhar, também humano, a que se convencionou denominar de científico e acadêmico, sobre o fenômeno da produção das línguas e da linguagem, sob responsabilidade das chamadas Ciências da Linguagem, institucionalizadas como Letras, Linguística e Linguística Aplicada ${ }^{9}$, aí inclusos estudos dos muitos e diversos aspectos que compõem os fatos ou fenômenos específicos da produção linguística humana. De modo mais particular ainda, podemos depreender espécies de subconjuntos de conhecimentos: Gramática e Estudo da Língua (normas, regras e descrição de formas e de usos), Leitura (estratégias e efeitos), Produção (descrição da construção dos produtos - som, léxico, palavra-vocábulo, frases-orações-sentenças-enunciados, textos e discurso). Sem a pretensão de listar exaustivamente os muitos componentes desses subconjuntos e sua relação com as diversas disciplinas e orientações teóricas que compõem esse universo, a menção, nesse caso, tem a finalidade apenas de auxiliar-nos na percepção do objeto a ser focado nesse trabalho.

No entanto, a menção a esse conjunto de conhecimentos não é aqui aleatória, uma vez que não há como se pretender a pensar língua como objeto de ensino sem apoio de uma concepção desse objeto fora do espaço de ensino. Aliás, para toda e qualquer situação de ensino, é necessário que se tenha minimamente conhecimento cognitiva e historicamente acumulado. Para o caso da língua, do senso comum, do leigo, ao especialista (RAJAGOPALAN, 2008), até as orientações oficiais, é possível encontrarmos respostas coerentes para perguntas como: o que é língua e o que se ensina e se aprende quando se estuda língua portuguesa na escola? Mas nos deteremos no âmbito dos conhecimentos científicos, ou seja, os que são produzidos como resultado de investigação na área a que, institucionalmente, se denomina de Linguística. Nessa área, como resultado de nossa

\footnotetext{
${ }^{9} \mathrm{~A}$ referência aqui é à denominação das áreas institucionalizadas, ora como cursos, ora disciplinas, em nosso sistema acadêmico, às quais cabe o estudo da língua e da linguagem humana.
} 
incursão pela Filosofia da Linguagem e da Linguística, destacamos pontos importantes para caracterizar a especificidade de Língua a ser considerada como objeto de ensino e, assim sendo, também como objeto de planejamentos de ensino, seguindo os princípios didáticos de finalidade e objeto da ação como os componentes fundamentais.

O primeiro ponto a destacar, com apoio da Filosofia da Linguagem, é a questão da natureza da linguagem como instrumento humano, geralmente apresentada, brevemente, em manuais de linguística ou em obras de divulgação de propostas para ensino de língua sob o rótulo de concepções de linguagem, de língua e de gramática. Segundo Auroux (1998), dois caracteres são fundamentais para o reconhecimento da linguagem humana: a qualidade física do som com as possibilidades de variação acústica e sua funcionalidade. É verdadeiro que o ser humano fala, ouve e sabe para que fala. $O$ acesso dos seres humanos a esse produto, o que sempre ocorre para todos, salvo em casos de impossibilidade física grave, lhe permite produzir dadas línguas. Essa produção natural se caracteriza por três propriedades: dupla articulação, marcação da subjetividade e a criatividade. Disso resulta, então, que conhecer uma língua é saber falá-la, o que provoca uma ambiguidade, segundo o autor, para a expressão "conhecimento linguístico", ou seja, conhecer uma língua é saber falá-la, mas isso não significa que o falante saiba explicá-la. Por isso, Auroux, retomando terminologia criada pelo linguista francês Antoine Culioli, nos aponta para dois tipos de conhecimento de/sobre língua, já amplamente divulgados em nossas instâncias acadêmica e escolar, cuja distinção acreditamos ser fundamental para pensar sobre a especificidade da língua como objeto de planejamento de ensino: o epilinguístico, referente ao saber "falar" uma língua e reconhecê-la como tal, e o metalinguístico, referente a uma linguagem como um conjunto terminológico para se referir ou representar partes da língua que o ser humano fala/escreve e dos usos e funções para as quais utiliza. Para que haja ciências da linguagem (especialmente, a Linguística, por ser a disciplina considerada de fundamentos para formação do professor de português), conforme Auroux (1998., p. 77), "é preciso que a linguagem seja colocada em posição de objeto [...], manifestação de si mesma e não de outra coisa, contrariamente ao que se passa em seu uso cotidiano."

Dessas considerações filosóficas, podemos depreender duas características da especificidade da língua a serem consideradas para sua colocação como objeto de ensino. A primeira, de natureza biológica, diz respeito a essa condição do ser humano para produzir uma determinada língua natural, sem a necessidade de intervenção do ensino formal escolar. A segunda, de natureza social, porque dependente de conhecimentos que se constroem/construíram nas relações entre seres humanos, diz respeito às formas, modos e propósitos de organização que compõem uma dada língua natural, como resultado do uso. A dependência do uso torna relativa a garantia da aprendizagem exclusivamente pela predisposição biológica, pois aprende-se a andar, a comer, e a falar com os outros e pela ação alheia. O pleno desenvolvimento do aspecto biológico também depende das relações sociais, principalmente dos conhecimentos que se mantêm, se transformam e se reconstroem nessas relações, e, por isso, determinadas capacidades no nível mental, 
cognitivo, precisam ser desenvolvidas, as quais estão para a supra capacidade da percepção, e esta só se constrói e se desenvolve plenamente por meio da linguagem e do uso de uma dada língua natural.

Assim, relacionando aos princípios constitutivos do ensino, do ponto de vista didático, se consideramos ser verdadeiro que o desenvolvimento da percepção, aqui compreendida como um conjunto complexo de conhecimentos da identificação referencial à compreensão, depende de acesso a esses conhecimentos e que a forma de desenvolvimento precisa de uma intervenção a ser feita de modo sistemático e gradual, teremos, assim, o primeiro componente da especificidade do ensino de língua: a constituição do aparato cognitivo que garantirá suporte para o desenvolvimento pleno da percepção. Isso será desenvolvido pelo processo conhecido por Leitura que se realiza no nível individual, na relação do indivíduo, como um sujeito sócio histórico e culturalmente situado, com os produtos de linguagem materializados em uma dada língua natural, a que denominaríamos de frases, orações, enunciados, textos e, mais recentemente, de gêneros textuais/discursivos.

Para o planejamento de ensino, esse componente, portanto, aponta objetivos de ensino que estão na ordem do individual, ou seja, para o desenvolvimento de capacidades de percepção e de compreensão, o que requererá, do ponto de vista da formação, apoio teórico de concepções de língua, de linguagem, de processamento psicolinguístico e de construção de sentido e significação, mas, do ponto de vista didático, é preciso ter clareza quanto a que finalidades nós, seres humanos, destinamos nossas ações de leitura no mundo: de modo geral, os objetivos de ensino de leitura, basicamente, devem se destinar a contribuir para o desenvolvimento da relação do sujeito (o aluno) com o material verbal em processo de leitura, fazendo acionar dois tipos de conhecimentos: a finalidade mesma da leitura e o objeto da percepção: $X$ é um fato, não é uma opinião. A opinião sobre o fato é de natureza conservadora, $O$ efeito do dito (posição conservadora) se manifesta por meio do uso de palavras e estruturas que aparecem na expressão linguística, a que se pode chamar de "texto", por exemplo.

Não estamos, com isso, reduzindo a concepção de linguagem e de língua natural à uma mera representação e à atividade do sujeito usuário a uma percepção passiva, ou contemplativa, lembrando Franchi (1992), de algo já dado como objeto conhecido, para o que a leitura teria a mera função de explicitar. Ainda com apoio de Franchi, seguindo o pensamento humboldtiano, é necessário considerar a função da linguagem não como apenas de transmissão de nossas experiências aos outros, mas a de constitui-las. Para o estudo das línguas naturais, esse postulado faz emergir o componente histórico da construção linguística, o qual será considerado, neste trabalho, associado ao caráter social da linguagem, uma vez que toda e qualquer formulação em uma dada língua natural está sempre na dependência da atividade humana; e esta é sempre uma atividade em interlocução: ouve-se ou lê-se o que outro produziu em determinados tempo, lugar e condições (mesmo que, fisicamente, o outro seja eu). 
No entanto, do ponto de vista didático, para fins de ensino-aprendizagem escolar, esse processo de percepção do mundo (Leitura) é cognitivo, por essência. Realiza-se, tendo uma dada língua natural como instrumento ou como um sistema organizador de possibilidades de formas perceptíveis e significativas, na relação direta do sujeito com o material. Por isso, o planejamento de ensino deverá estar orientado para essa especificidade: a da relação do aluno com o material linguístico, a ser inscrito como texto ou como gênero textual ou discursivo, para o desenvolvimento de seus conhecimentos sobre o que compõe o e o que se pensa sobre o mundo e sobre a linguagem e língua que enformam tais conhecimentos. Dessa especificidade, é possível depreender os dois conteúdos fundamentais do ensino de leitura: a referência ou referenciação e sentido ou significação, em dois sentidos em direção à língua: interno e externo.

O segundo ponto é a natureza da linguagem como produto da expressão linguística humana. Segundo Castilho (2010, p. 41), "lidar com uma língua natural é operar com um objeto científico 'escondido'". Seguindo o mesmo autor, é importante lembrar que linguistas e gramáticos operam com um objeto guardado na mente das pessoas e, por isso, não evidente como um objeto do mundo real. A que o estudo da língua/linguagem tem acesso é, portanto, expressões possíveis desse objeto mental. Certamente, não cabe aqui desenvolver esse tópico, já amplamente desenvolvido em literatura específica da Filosofia da Linguística. Apenas retomamos como postulado para trazer à tona outra importante característica da especificidade da língua/linguagem como objeto de ensino. A diversidade teórica, como consequência da tentativa de explicação científica dos fenômenos linguísticos, além de ser uma evidência dos distintos lugares ou pontos de vista de onde tais fenômenos são percebidos pelos estudiosos, comprova também que língua/linguagem não tem fim em si mesma, mas existe $(\mathrm{m})$ como resultado de sua utilização pelos seres humanos, nas relações entre si, em espaços e tempos determinados, para atender a determinadas finalidades. Em suma, é um produto de natureza social, porque sua existência e seu funcionamento dependem dessa utilização, a despeito de toda tentativa de descrição exaustiva ou de normatização. A essa utilização podemos chamar, genericamente, de Produção que sempre reclamará mais de um indivíduo para que se realize, embora se possa localizar no mundo a origem do que os filósofos chamam de expressão do ser (DELEUZE, [1969]2000) e atribui-la a um único indivíduo, como primeiro produtor da manifestação verbal.

No entanto, como já sabidamente comprovado pelos estudos linguísticos, essa produção só pode ser considerada individual de ponto de vista meramente físico: aquele que fala (de onde ou de quem parte a emissão de som) ou aquele que escreve/digita (de onde ou de quem parte a construção gráfica). Seja qual for a perspectiva ou o foco ou o aspecto em evidência, língua e linguagem serão consideradas como produtos de interlocução, situados sócio historicamente, sob condições culturais e ideológicas de usos e de sentidos a se manterem, se renovarem, se transformarem, sendo moldadas por esses mesmos usos, por sujeitos que agem em função de determinados fins sociais. Também do ponto de vista filosófico, não há como limitar a natureza linguística à expressão vocal, pois como afirma 
Deleuze ([1969]2000, p. 187), o que torna a linguagem possível não é o som (ou a escrita; acréscimo nosso) nem a manifestação ou a proposição (no sentido do que se diz sobre o mundo), mas o acontecimento que torna possível designar, manifestar e significar. Grosso modo, podemos dizer, então, que é esse o princípio orientador da produção linguística/de linguagem. Ora, como essa produção dependerá muito mais do exterior ao indivíduo que produz, resultará, por isso, em algo sempre sujeito aos efeitos de uma dada situação (o que é/acontece; quem fala/escreve; para quem; onde, quando, por que...), sendo o resultado do estudo descritivo (a que se convencionou denominar de Linguística) o complexo conjunto epistemológico e terminológico que bem conhecemos. Para o ensino, e suas implicações para as situações de ensinar/aprender a planejar, a impressão é que haveria tantos modos de planejar ensino quantos são os modelos teóricos de análise da língua. Assim: um ensino textual, um ensino sociolinguístico, um ensino discursivo, um ensino pragmático, um ensino sócio discursivo, um ensino sócio retórico, um ensino funcionalista; e todos rivais do ensino estrutural, sendo este, quase sempre, tomado como equivalente a ensino tradicional de gramática.

Como dissemos antes, esse conjunto de postulados filosóficos nos coloca diante da segunda característica específica da linguagem e de uma língua natural que é a sua natureza social de realização. Sabemos, também, que, assim como do ponto de vista biológico (ou psíquico/mental, para se referir ao que é de natureza estritamente individual), o ser humano não precisa do ensino formal para aprender a produzir um certo conhecimento de base, a que filosoficamente, poderíamos denominar de designação, por exemplo (DELEUZE, [1969]2000). A sequência sonora ou gráfica que resultaria para gerar, em português brasileiro, a expressão que designa um determinado ser pode pai, e, ao fazer isso, uma determinada manifestação apoiada/acompanhada em/por uma significação estaria se mantendo, para se referir ao ser humano masculino gerador biologicamente de outro. Mas, essa é apenas uma possibilidade de significação. O fato importante a ser destacado aqui é "a percepção reclama a produção", ou seja, para que se percebam sentidos e significados, e, portanto, haja Leitura, é preciso que estes tenham sido produzidos. Para isso, o ato linguístico se constitui o material fundamental, o qual, embora produzido por um indivíduo, sempre partirá e se destinará de e para seu exterior. A esse processo, podemos denominar, sob esse ponto de vista, de Produção, que não se confunde com "produzir textos em substituição a escrever redação".

Para o planejamento de ensino, esse componente, a Produção, aponta objetivos que estão, portanto, na ordem do coletivo, dialógico, ou seja, para o desenvolvimento de capacidades de realização linguística adequada, interpretável e compreensível. Para a formação acadêmica, concepções de gramática, texto, discurso, além de conhecimentos específicos sobre variação linguística, descrição linguística (fonética, morfologia e sintaxe), organização de unidades textuais, utilização de recursos discursivos, argumentação, entre outros mais específicos, constituem o apoio teórico por excelência. É o lugar dos estudos da língua e da linguagem (Linguística e subáreas e as Gramáticas). 
Para o planejamento de ensino escolar, os objetivos de ensino da Produção Linguística/de Linguagem devem se destinar a contribuir para o desenvolvimento da relação do sujeito (o aluno) com os propósitos das realizações de linguagem, ou tendo como foco principal o para quê utilizamos língua, nas diversas situações de interlocução entre humanos. O princípio norteador da produção linguística, filosoficamente orientado, diferente mas complementar em relação à leitura, é a relação do sujeito com outro, ou com outros, ou ainda consigo, mas tendo o mundo externo como lugar de expressão, onde deverá ocorrer o processo de percepção do produzido, bem como de todos os possíveis efeitos daí gerados. Se para Leitura, os conteúdos fundamentais seriam referenciação e significação, para a Produção Linguística (de Língua)/de Linguagem, os conteúdos, sob esse ponto de vista, seriam a própria realização linguística e a sua diversidade de manifestação e de organização.

\section{Considerações finais}

Como prática social, a ação de planejar reclama um agente e um objeto para ou sobre o qual devem se dirigir as atividades empreendidas. Se a ação final é ensinar, esperase, como produto, um objeto ensinado. Nesse sentido, o objeto específico, para o caso aqui em foco, é língua. Espera-se ensinar língua ou os conhecimentos de ou sobre língua? Ou os dois? No entanto, como objeto científico de investigação, língua pode ser código, estrutura, processo mental, produto e processo histórico, textual e discursivo (CASTILHO, 2010), a depender do tipo de fenômeno observado pelo ponto de vista de observação teóricoanalítico. Desse universo, um conjunto complexo de conhecimentos, não necessariamente consensuais, se constitui a respeito desse objeto amplo: língua. Para pensarmos sobre sua especificidade como objeto de ensino, é preciso pôr em evidência o que os seres fazem com ele, para que se tenha mais segurança na determinação dos pontos de partida e de chegada, de modo semelhante ao que ocorre em qualquer outro tipo de planejamento.

Da ciência ou do conhecimento de referência (SAVIANI, 2010) só se pode buscar o que for pertinente e adequado aos fins de ensino para a educação formal escolar. Não interessa, por exemplo, o conhecimento produzido para distinguir Fonética de Fonologia, Texto de Discurso, Sociolinguística de Psicolinguística, Morfologia de Sintaxe, mas interessa saber que conhecimentos originários de todos esses lugares de produção, todos muito importantes, deverão estar a serviço dos objetivos de ensino. Dito de outro modo, se aceitamos a língua como um instrumento que nos ajuda a compreender o mundo em que vivemos, certamente, um objetivo de ensino será, de forma geral, favorecer o reconhecimento e o uso desse instrumento nas situações concretas da vida social. Guiado, então, por esses postulados e princípios filosóficos que nos ajudam a depreender a especificidade da língua do ponto de vista da relação com o ser humano, propomos, nesse trabalho, pensar planejamento de ensino de língua, na interface Educação, Estudos de 
Linguagem e Filosofia, para daí definir os componentes didáticos fundamentais: objetivos e conteúdos. Nesse caminho, chegamos a dois objetivos fundamentais de ensino e, portanto, regedores de todo e qualquer planejamento: perceber/compreender e produzir língua/linguagem, o que nos conduz a dois grandes eixos de conteúdo: Leitura e Produção. Este último não limitado ao que se concebe apenas como "produção textual" em substituição a "redação", mas o conjunto de conhecimentos linguísticos (inclusive, o de falar e o de escrever) necessário à efetiva percepção do mundo pela língua e linguagem, mediado por seus diversos produtos.

A construção desse pensamento está guiada pela ideia de especificidade linguística que se manifesta, conforme tentamos mostrar, em função de dois tipos de relações entre o ser humano e a língua/linguagem: do sujeito em relação ao objeto língua/linguagem e das relações entre os sujeitos mediadas pelo objeto, aos quais correspondem, respectivamente, Leitura e Produção.

Com isso, pretendíamos, não apenas sinalizar uma possibilidade de reflexão para enfrentamento de questões corriqueiras sobre a dificuldade de se planejar ou se ensinar a planejar, mas também o lugar do conhecimento teórico na formação acadêmica. Quanto à primeira, não se pode sustentar afirmações sobre não se saber o que planejar porque, quanto a língua/linguagem, ensina-se a ler e a produzir. Para a formação, acreditamos ter ressaltado a preservação do lugar de estudo da língua/linguagem e a construção desse conhecimento de interface, porém, relativamente autônomo, mantendo como princípio de orientação a especificidade do que será ensinado e não o que determinada(s) teoria(s) linguística(s) está(ria) propondo como modelo de descrição de fatos ou fenômenos linguísticos/de linguagem.

\section{Referências}

ALARCÃO, I. Contribuição da Didática para a formação de professores - reflexões sobre seu ensino. In: PIMENTA, S. G. Didática e formação de professores: percursos e perspectivas no Brasil e em Portugal. São Paulo: Cortez Editora, 2011, p. 179-214.

ANDRÉ, M. E. D. A. de. Tendências no ensino de didática no Brasil. In: PIMENTA, S. G. Didática e formação de professores: percursos e perspectivas no Brasil e em Portugal. São Paulo: Cortez Editora, 2011, p. 215-230.

AUROUX, S. A Filosofia da Linguagem. Campinas, SP: Editora da UNICAMP, 1998.

BARBOSA, M. V., FERNANDES, N. A. M. Políticas públicas para a formação de professores: Pibid, Mestrados Profissionais e PNEM. In: Em Aberto. Brasília. v.30, n. 98, p. 23-39, jan/jun 2017. https://doi.org/10.24109/2176-6673.emaberto.30i98.3195

BORGES NETO, J. Ensaios de filosofia da Linguística. São Paulo: Parábola Editorial, 2004.

CASTILHO, A. T. de. Nova Gramática do Português Brasileiro. São Paulo: Contexto, 2010. https://doi.org/10.11606/issn.2176-9419.v13i1p7-16 
CHARLOT, B. Da relação com o saber: elementos para uma teoria. Porto Alegre: Artes Médicas Sul, 2000.

COLL, C. Aprendizagem escolar e construção de conhecimentos. Porto Alegre: Artmed, 2002.

DELEUZE, G. Lógica do sentido. 4. ed. São Paulo: Perspectiva. [1969]2000.

DORNELLES, C. A reforma curricular e o debate sobre língua portuguesa e ensino no curso de Letras. In: SIGNORINI, I., FIAD, R. (orgs). Ensino de língua: das reformas, das inquietações e dos desafios. Belo Horizonte: Editora UFMG, 2012, p. 122-144.

FILLOLA, A. M. Didáctica de la lengua y la literatura. Madrid: Pearson Educación, 2003. Disponível em: https://books.google.com.br/books. Acesso em 15 de setembro de 2017.

FRANCHI, C. Linguagem - atividade constitutiva. Cadernos de Estudos Linguísticos, n. 22, p. 9-40, jan./jun. 1992.

GERALDI, J. W. (org.) O texto na sala de aula: leitura \& produção. 2 ed. Cascavel: ASSOESTE, 1984.

GIDDENS, A. A constituição da sociedade. São Paulo: Martins Fontes, [1984]2009.

LIBÂNEO, J. C. Didática. 2.ed. São Paulo: Cortez, 2013.

LIBÂNEO, J. C. Educação: pedagogia e didática - o campo investigativo da pedagogia e da didática no Brasil: esboço histórico e buscas de identidade epistemológica e profissional. In: PIMENTA, S. G. Didática e formação de professores: percursos e perspectivas no Brasil e em Portugal. São Paulo: Cortez Editora, 2011, p. 89-148.

LUCKESI, C. C. Avaliação da aprendizagem escolar: estudos e proposições. 22. ed. São Paulo: Cortez Editora, 2011.

MARTELOTTA, M. E. Funções da linguagem. In: MARTELOTTA, M. E. (org.). Manual de Linguística. São Paulo: Contexto, 2009, p. 31-36.

PIMENTA, S. G. Didática e formação de professores: percursos e perspectivas no Brasil e em Portugal. São Paulo: Cortez Editora, 2011.

OLIVEIRA, M. R. N. S. A pesquisa em didática no Brasil - da tecnologia do ensino à teoria pedagógica. In: PIMENTA, S. G. Didática e formação de professores: percursos e perspectivas no Brasil e em Portugal. São Paulo: Cortez Editora, 2011, p. 149-178.

PIMENTA, S. G. Para uma ressignificação da didática. In: PIMENTA, S. G. Didática e formação de professores: percursos e perspectivas no Brasil e em Portugal. São Paulo: Cortez Editora, 2011, p. 15-23.

RAJAGOPALAN, K. O santo graal da Linguística. In: SIGNORINI, I. (org). Situar a lingua[gem]. São Paulo: Parábola Editorial, 2008, p. 15-38.

RAJAGOPALAN, K. Por uma lingüística crítica. São Paulo: Parábola, 2003.

SACRISTÁN, J. G., GÓMEZ, A. I. P. Compreender e transformar o ensino. 4. ed. Porto Alegre: Artmed, 1998.

SAVIANI, N. Saber escolar, currículo e didática. 6.ed. Campinas, SP: Autores Associados, 2010.

SCHNEUWLY, B.; DOLZ, J. Gêneros orais e escritos na escola. Campinas, SP: Mercado de Letras, 2004. 
SOARES, M. B. Que professor de português queremos formar? In: Boletim da ABRALIN. Fortaleza. N. 25. 2000, p. 211-218.

UFCG. Projeto Pedagógico Curso de Licenciatura em Letras: Língua Portuguesa. Campina Grande: Unidade Acadêmica de Letras, 2011.

ZABALA, A. A prática educativa: como ensinar. Porto Alegre: Artmed, 1998.

Recebido em: 30/08/2018

Aceito em: 20/02/2019 